\title{
SÃO FRANCISCO DE ASSIS, UMA TRADIÇÃO E A ANÁLISE TEMÁTICA DO "CANTICO DELLE CREATURE"
}

\section{Vilma K. Barreto de Souza}

São Francisco, apesar de exaltar os homens idiotas e iletrados, muito amou e respeitou as letras. Tommaso da Celano (1) conta que o Seráfico recolhia qualquer "rotuletto" e pedaço de pergaminho que estivesse pelo chão, temendo pisar sobre o nome do Senhor. ou sobre algum trecho que falasse de coisas divinas. $\mathrm{E}$, quando um seu discípulo lhe perguntava por que recolhia com tal cuidado os escritos dos pagãos, ter-lhe-ia respondido "Fili mi, litterae sunt exquibus componitur gloriosissimum Dei nomen" e, depois acrescentava que, o que em tais escritos podia ser bom, não pertencia aos pagãos nem aos outros homens, mas só a Deus, de quem procede todo o bem.

Desse modo genialíssimo Francesco respeitava todas as literaturas sacras e profanas, como o mais iluminado humanista. E depois, é sabido que ele gostava de falar e de cantar em francês. Está fora de dúvida que ele conhecesse bem os romances de cavalaria franceses; de outro modo não se explicariam tantas alusões, nos seus discursos, a imagens cavalheiresco.

Falando de Frei Egídio, com os seus confrades, exclama "Eis o nosso Cavaleiro da Távola Redonda"!

Carlos Magno, Orlando, Olivier e "tutti i paladin" são lembrados no Speculum Perfectionis (2) e, é dito no mesmo Speculum que os bons frades devem saber operar o bem, e rezar na solidão para não assoberbar as vaidades: nessa ocasião são chamados "i fratelli miei, cavalieri della Tavola Rotonda", estes são os meus irmãos cavaleiros da Távola Redonda, que se mantêm escondidos em \footnotetext{
relli, 1950 .

(2) - Gli Scritti, S. F d'Assisi, Assisi Porziuncola, 1975.
}

(1) - Lo Specchio di Perfezione, volg. da F. Pennacchi, Roma, Signo-

Língua e Literatura, (15), 1986. 
lugares desertos, ocultos para esperar com maior cuidado a ação e a meditação"

Ora, somente um leitor assíduo dos romances de cavalaria, observou Pio Rajna, poderia estar bem por dentro, sob este particular, do segredo da operação dos cavaleiros, que vão pelo mundo, escondendo o seu ser e cumprindo grande gesta: Lancelote é chamado o "bel valletto", e, mais tarde, se tornará o "cavalier bianco" São anônimos e desconhecidos para o mundo, como deveriam ser os seguidores do santo frade.

A familiaridade com os romances de cavalaria é atestada pela educação e pelo gosto cavalheiresco que teve Francesco, quando jovem, e os biógrafos o descrevem como o princípe da juventude, pela elegância do vestir-se e pela alegria; e, também, na sua nova vida religiosa ele idealiza, sempre, esse título de cavaleiro. Tommaso da Celano chama-o "novus Christi miles", "fortissimus miles Christi", e São Boaventura invoca-o como "strenuissime miles Christi" "dux in militia Christi" condecorado com "crucis in signibus" armado com "armis coelestibus"

Como se sabe, "miles" e "militia" na latinidade medieval, significam, exatamente, "cavaleiro" e "cavalaria"

Ainda um traço da sua educação literária e romancesca, e do seu gosto cavalheiresco temos na figura tão criativa, e que lhe foi tão querida, das núpcias com a Senhora Pobreza: não existe cavaleiro sem dama, e a dama do cavaleiro de Cristo é a Pobreza.

São Boaventura diz-nos que Francesco chamava a pobreza "modo matrem, modo sponsam, modo dominam", e se compreende de que modo se introduzisse pelos biógrafos o mito da mãe e da esposa, unido ao da dama, querendo excusar, em uma imagem mais casta e menos profana, as relações de Francisco com a Pobreza. Mas, também, é significativo que Dante, imune às preocupações hagiográficas, falasse, assim das núpcias de francesco com a pobreza, como se foram amantes:

\section{"Francesco e Povertá per questi amanti prende oramai nel mio parlar diffuso"}

(Commedia, Par XI, 74, 75).

Assim, não é ousada a conjectura de Rajna, quando supõe que "a Francesco, a Pobreza apareceu como a dama dos seus pensamentos, não o contrário do que foi Ginevra para Lancelote"

Um outro testemunho da cultura de Francesco d'Assisi estaria, também, na adoção, no Cantico delle Creature, se é verdade que 
o per, repetido sete vezes, pode ser comparável ao par francês, e ao per, complemento de agente do italiano antigo, que estará, depois, também, no italiano de Dante:

"Fur l'ossa mie per Ottavian sepolte" ;

"Intanto voce fu per me udita";

"Più era già per noi del mondo volto" (3).

Pense-se na genial interpretação, que, do Cantico deu Luigi Foscolo Benedetto (4). Mas deixemos esta elevada testemunha de lado, bem como do per como par: é uma boa atitude do poeta douto privar com fontes e modelos literários.

E sabido que o Cantico foi imitado, e, em certos pontos, literalmente, do Cântico de Daniel, dos Três Meninos na Fornalha Ardente e do Salmo 98 de Davi.

Conclui-se que o Santo não foi um "homem idiota e de muitas letras" A idiotia por ele elogiada era, somente, a simplicidade e a humildade do espírito e da mente.

E, portanto, falso que o primeiro monumento da literatura italiana tenha nascido da inspirada ignorância da santidade.

SÃO FRANCISCO DE ASSIS - "CÂNTICO DAS CRIATURAS" (traduzido do texto do manuscrito 338 da Biblioteca Comunale di Assisi, o qual data dos primeiros decênios do séc. $\mathrm{XV}$ ).

Altíssimo, onipotente, bom Senhor,

Teus 'são o louvor, a glória, a honra

E toda a benção.

Só a Ti, Altíssimo, são devidos;

E homem algum é digno

$\mathrm{De} \mathrm{Te}$ mencionar.

Louvado sejas, meu Senhor,

Com todas as tuas criaturas,

Especialmente o senhor Irmão sol,

Que é luz diurna

E por ele Tu nos iluminas;

E ele é belo e radiante

Com grande esplendor:

$\mathrm{De} \mathrm{Ti}$, altíssimo, é imagem.

(3) e (4) - Cfr. Pio Rejna in Benedetto, Luigi F., Il Cantico di Frate Sole, Firenze, Sansoni, G. C., Ed., 1941. 
Com a Irmã Lua e as estrelas, Louvado sejas, meu Senhor, Que no céu formaste claras E preciosas e belas.

Louvado sejas, meu Senhor

Com o Irmão vento,

E como o ar e todo o tempo,

Nublado ou reseno,

Pelo qual às tuas criaturas

Dás sustento.

Louvado sejas, meu Senhor,

Com a Irmã água,

Que é mui útil e humilde

E preciosa e casta.

Louvado sejas, meu Senhor,

Com o Irmão fogo,

Pelo qual iluminas a noite.

E ele é belo e jocundo

$E$ vigoroso e forte.

Louvado sejas, meu Senhor,

Com nossa Irmã a mãe terra,

Que nos sustenta e governa,

E coloridas flores e ervas.

E produz frutos diversos

Louvado sejas, meu Senhor,

Com os que perdoam por teu amor,

E suportam enfermidades e tribulações.

Bemaventurados os que as suportarem em paz,

Porque, por Ti, Altíssimo serão coroados.

Louvado sejas, meu Senhor,

Com a nossa Irmã morte corporal

Da qual nenhum homem vivo pode escapar.

$\mathrm{Ai}$ daqueles que morrerem em pecado mortal!

Felizes os que ela achar

Conformes à Tua santíssima vontade,

Porque a morte segunda lhes não fará mal!

Louvai e bendizei ao meu Senhor

E dai-lhe graças

E servi-o com grande humildade. 


\section{ANÁLISE TEMÁTICA DO "CANTICO DELLE CREATURE"}

No ano do oitavo centenário de nascimento de São Francisco de Assis, quase todos os que o conhecem pela fama de santidade, mais ou menos envolvidos pelas lendas religiosas ou profanas, sabem que a vida do Seráfico Patrono da Itália é simples e luminosa como foi a sua obra e a sua história. Nascido em Assis, em 1182, morreu aos quarenta e quatro anos, em 1226 , junto à sua predileta igrejinha da Porciúncula.

Apareceu num século violento e bélico, como uma suave reencarnação de Cristo, homem entre homens. Pregou, sobretudo, o amor, a pobreza e a humildade; recebeu sobre a nua rocha de Verna, entre o Tibre e o Arno, os estigmas da cruz. Fundou a Ordem dos Frades Menores, confirmada pelos Papas Inocêncio III e Honório III; a Ordem Franciscana Feminina de Santa Clara e, ainda, a Ordem Terceira da Penitência.

Toda a sua obra e toda a sua vida são pura Poesia. Além da Regra da Ordem parece não ter escrito muito mais.

IL CANTICO DELLE CREATURE, OU LAUDES CREATURARUM, IL CANTICO DI FRATE SOLE ou CANTICUM FRATIS $S O L I S$, este último como o Santo preferia chamar, (Benedetto, op. cit., p. 220) é um salmo ou um hino de glória a Deus e à toda a obra da criação. Não lhe saiu da pena, mas dos pálidos lábios e da santa alegria do seu coração: Quase cego, e próximo da morte, cantou-o, e esse canto, repetido pelos frades menores e pelos devotos permaneceu, em várias edições umbras ou abrucezas, na sua grandeza ingênua.

Voz de um Santo e a primeira Voz da poesia italiana.

Durante a juventude tumultuada e dedicada aos prazeres, mas na qual teve boa educação literária, como já vimos, com discreto conhecimento do latim e do francês, o jovem Francisco, além do gosto pela língua e pelo canto, transformou-os em instrumentos altissonantes da sua vida e do seu exemplo.

É significativo, entre outras, por essa razão, que o primeiro texto de tradição italiana seja um autêntico monumento literário e não só linguíśstico, e que tenha brotado de um movimento religioso inovador e animado por profundo fermento popular, qual seja o franciscanismo, ou a exigência de uma religiosidade aderente à palavra 
clo Evangelho, à exaltação da pobreza e da humildade, à polêmica contra a orgulhosa sabedoria humana (5)

Tudo isso deve ter induzido São Francisco a escolher, para exprimir o próprio ardor religioso, não a língua dos eruditos, mas aquela das relações cotidianas, a língua em que ele projeta uma imagem serena e otimista da vida, em contraste e em oposição à maior parte das concepçōes medievais, sem a amargura e o temor das terríveis penas infernais; tudo da vida ele aceita com brandura e amor: o bem, o mal, o belo e o feio, porque tudo é caro ao Senhor; ele chega a esta serena imagem, não por passividade, mas por exuberância espiritual, por uma conquista de cada dia, que doma nele $o$ instinto, e o transforma.

De tal maneira ele realiza o ideal cavalheiresco no qual foi educado, humanizando-o e estendendo-o a todas as criaturas vivas ou inanimadas, criadas por Deus, que tudo se transforma num ato de amor fraterno e num rito de alegria.

Nesse seu reconhecimento de Deus em todas as coisas e no amor de cada uma delas porque obras de Deus, poder-se-ia ver um reflexo do panteismo cristão, vivo e operante no coração do Santo, por instinto, e por uma graça que vai além de toda a crença religiosa (6).

Isto nos parece importante para sublinhar uma obra, que, pela sua admirável harmonia, teve conseqüências notáveis no espírito italiano, e influenciou, profundamente, uma direção da literatura peninsular, vida essa que, por si só, como já se disse, é uma alada poesia, uma completa obra de arte.

Extrai-se de todos os seus escritos, apesar de poucos, um misticismo, que é profundamente poético, em especial, desse Cântico do Irmão Sol, sobre o qual se discute tenha sido escrito em latim (7) ou em vulgar, mas, que tudo deixa ver, tenha brotado do seu espírito na linguagem dos humildes do seu tempo, e da região onde nasceu, a Úmbria, para que todos o compreendessem e o repetissem.

Sob o nome de São Francisco, só permaneceram algumas obras em latim: a Regula, o Testamentum, as Admonitiones e as Laudes Dei e pouco mais.

(5) - Getto, A. B. de R., Storia della Lett. Italiana, Milano, Rizzoli Ed., 1970.

(6) - Lazzeri, G., Antologia dei primi sec. della lett. italiana, Milano, U Hoepli, 1954. 1941 .

(7) - Vossler, K. Hist. de la Lit. Italiana, Barcelona, Ed. Labor, 
Contudo, o Cantico di Frate Sole, escrito em dialeto umbro, é profundamente inspirado nas Sagradas Escrituras, é composto de uma prosa fortemente assonântica, rítmica, inteiramente impregnado de correspondências íntimas, espirituais, nasceu de um fundo de cultura. Segundo a lenda franciscana, foi composto em 1224, dois anos antes da morte do santo, depois de uma noite de angustiantes sofrimentos físicos, confortada, ao fim, por uma visão de beatitude celeste.

\section{O gênero poético do Cântico}

Dentre as categorias retóricas da época, isto é, a poesia métrica (s6 possível na poesia latina) e a poesia rítmica mesclada à prosa, São Francisco escolhe só a prosa. É a prosa rítmica em forma hinológica, do tipo ambrosiano, que se conota não pela rima, mas pelo isossilabismo de versos predominantemente breves. Contudo, o poeta entra na fenomenologia dos "primitivos", uma vez que na cultura deles, segundo a tipologia das "origens" pesquisada, em particular, por Norden, não se polariza de modo tão irremediável a oposição de prosa e poesia (8).

Por uma coincidência bem cristã, também, a palavra divina transcende a oposição de prosa e poesia: ela não tem necessidade de efeitos postiços, nem mesmo da medida ou da métrica. Entretanto, são figuras memoráveis, desde os Salmos evangélicos, que, certamente, inspiraram a elaboração do Cântico, a anáfora, retomada ao início de cada estrofe Laudato si' mi Signore e a repetição da conjuntura et nas enumerações, especialmente na forma de variações, que é a rima "retórica" Imitando os textos sacros, São Francisco aproveitou os elementos de um estilo bem individualizado, o chamado isidoriano (Contini, op. cit.) (9).

Por que a língua vulgar?

Extensão semelhante, desvinculada de qualquer consideração ideológica, parece ser intimamente inerente ao tema da Laude, o qual por si implica sutilezas dialéticas, como provará, no fim do século, Dante, na paródia erótica, nas rimas da laude. O raciocínio, ou seja, o silogismo que se pode inferir é o seguinte "onmis creatura", toda a espécie de palavra é tributária de louvor ao Senhor, logo, não só 1970 .

(8) - Contini, G. Varianti e alrta linguistica, Torino, Einaudi Ed.,

(9) - . "chiamerò 'isidoriano', cioè la costruzione simmetrica, sottolienata da copiose rime dezinenziali (-endo, -amus e così via)" in "Un'ipotesi sulle Laudes Creaturarum", p. 151. Devoto G., Oli G. C. Diz. della Ling. Italiana, Firenze, Le Monnier, 1971. 
a palavra latina, mas também, a humílima e incôndita palavra vulgar "in qua et muliercule communicant" deve participar do coro (Contini, op. cit., p. 158).

Até aqui, prossegue Contini, caberia ao Cântico, apenas uma retórica involuntária, aquilo que se poderia chamar "isidorismo" por força maior; mas um primeiro acréscimo, que se pode fazer, é o da rima ou assonância, que não conota, necessariamente, a poesia, mas, ao contrário, coincidindo com uma isocolia aproximativa (10), é um antigo requisito da prosa de arte. Esse acréscimo de rimas dentro do Salmo já é uma inovação importante; o ulterior acréscimo de um "cursus" (11), outra conotação da prosa artística, constitui uma integração do conjunto .

Poder-se-ia, ainda, dizer que a prosa de São Francisco, ao estilo gregoriano, já se ressentia do aparato e da dignidade das escrituras civis e eclesiásticas, especialmente, em que as cláusulas rítmicas tendem a substituir as quantitativas. Usar, se não ostentar o "stilus Romanae Curiae" é, no contexto franciscano, uma prova de conformidade e de obediência.

"A retórica interna das Laudes creaturarum é uma retórica eminentemente ortodoxa" (id., ibid.).

Para a análise da obra usaremos o texto do masi antigo códice que chegou até nós: o manuscrito 338 da Biblioteca Comunale di Ássisi, dos primeiros decênios do séc. XV

\section{O TEMA DE LOUVOR A DEUS E O TEMA DE LOUVOR ÀS CRIATURAS}

Como uma sugestão de análise, poderíamos destacar os planos espaciais do Paraíso, sonhado por São Francisco:

(10) - Cfr. "isocòlo" s.m. - figura della retorica classica che consiste nella perfetta corrispondenza fra due o più membri di un periodo per numero e dispozione di parole;

(11) - "cursus" - Andamento ritmico del periodo, caratterizzato da clausole o succesioni di accenti, che adattano all'orecchio moderno le cadenze della prosa latina classica, fondate invece, sull'alternanza di sillabe lunghe e brevi. Codificato alla fine dell'XI sec. nelle Artes dictandi, ebbe influsso anche sulla prosa volgare del Due e del Trecento. 


\section{CANTICO DELLE CREATURE (1224)}

1 Altissimu, onnipotente, bon Signore tue so le laude la gloria e l'honore et onne benedictione.

4 Ad te solo, Altissimo, se confano (EMPIREO) et nullu home ene dignu te mentovare

Na Abertura, a que chamamos de Paraíso Celestial ou Empíreo, Deus é o mais alto, o todo-poderoso, e a fonte suprema da bondade: a Ele pertencem o louvor, a glória, a honra e toda a benção, devidas pelo homem, que, apesar de ser a única criatura dotada da capacidade da palavra, é indigno de mencionar o seu santo nome.

$\mathrm{Na}$ seqüência dos três adjetivos com que se abre o poema sentimos o terceiro como o mais forte e o que detém o ímpeto rítmico inicial; mas é o primeiro que estabelece e determina o espaço celestial: "altissimo", o mais alto, o supremo.

Quanto à indignidade da palavra humana, mais tarde, Dante confirma, nestes versos do seu Paradiso:

"O somma luce che tanto ti levi
da" concetti mortali, alla mia mente
ripresta un poco di quel che parevi,
e fa la lingua mia tanto possente,
ch'una favilla sol della tua gloria
possa lasciare alla futura gente"

(Par. XXXIII, 67 a 72). "che ciò ch'i' dico è un semplice lume"

Dos versos 6 a 12, a que chamamos de PARAISO SIDERAL, depois da abertura solene, o segundo plano espacial está contido no céu e nas suas criaturas:

6 Laudato sie, mi Signore, con tutte le

PARAISO tue creature SIDERAL spetialmente messor lo frate sole lo quale jorna et allumini noi per loi. Et ellu è bellu e radiante cum grande splendore de te, altissimo porta significatione.

(Céus do Sol, da Lua e das Estrelas) 1983

(12) - Alighieri, D. La Divina Commedia, Milano, U. Hoepli Ed., 
Laudato si', mi Signore, per sora luna e le stelle,

in celu l'ai formate clarite et pretiose et belle.

O concerto do mundo criado, ou seja, o conjunto de todas as obras divinas que são exortadas a unirem-se, e são louvadas com o Senhor, abre-se, nesse espaço, com o primeiro louvor que é para "messor lo frate sole" enquanto representa no mundo o fulcro de toda a energia, que possibilita a vida assemelhando-se a Deus, como fonte da luz, e que é ao mesmo tempo, o irmão radioso e esplendente.

Pode-se observar, neste passo, o emprego das duas preposições, que tem dado oportunidade a muitas reflexões, não apenas de caráter puramente lingüístico, mas também de interpretação semântica, o que nos permitiu optar pela que nos pareceu mais viva, original e que dá, certamente, a todo o poema a sua originalidade e o alto grau poético de uma nova visão artística possível, no plano do Santo.

A preposição cum (con) e a preposição per

Segundo a mais antiga interpretação, a preposição per traduzia-se por propter, for, für ou $a$, para; a segunda tradução seria: quoniam, a causa di, a cagione di, porque, por causa de. Uma terceira tradução é a que faz corresponder per à preposição de meio, regendo o complemento de agente, e é como se traduz o verso 8:

(= por ele, por meio dele, etc.), $d a, a b$ par: é esta a tradicional, corrente ao tempo de São Francisco, a da Igreja e a da maior parte de seus biógrafos (Benedetto, Il Cantico di Frate Sole).

"lo quale jorna et allumini noi per loi"

Mas o emprego de que nos servimos é a que atribui a per, o sentido de in, isto é, em, através de, que está no Speculum Perfectionis, de Frate Leone, cap. XVIII, 68 (ap. Benedetto, op. cit., p. 45).

Também para a preposição cum adotamos o sentido de "insieme cum tutte”, que é o da maioria dos seus intérpretes (13).

(13) - Casella, Contini, Ricci in Storia della lett. ital., C. Salinari Ricci, Roma-Bari, Laterza Ed., 1973, $1^{\circ}$ vol. 
Voltando à análise do texto, com o esplendor do sol jorra, também, a energia do grande sentimento, novo em relação às criaturas inanimadas até aqui, que é o sentimento de fraternidade, comovente e simples como elas.

Todas as imagens de claridade, de esplendor e de luminosidade identificam, num só arrebatamento do poeta, o brilho interior com que cantou e ditou aos confrades o lirismo de um momento de sua vida, em que se achava quase inteiramente cego.

Dos versos 13 ao 23 localizamos o PARAISO TERRESTRE, pois, à medida que o poeta baixa o olhar, aparecem as criaturas, que se movem no espaço aéreo: é o irmão Vento e o tempo nas suas variações estivais e hibernais, sugerindo as estações do ano, nas quais se sucede a vida: todos são dignos de louvor, porque são um prolongamento do Senhor:

13 Laudato si', mi Signore, per frate vento et per aere et nubilo et sereno et onne tempo per lo quale a le tue creature dai su stentamento.

Laudato si', mi Signore, per sor'acqua

la quale è multo utile et humile et pretiosa et casta.

PARAISO

Laudato si', mi Signore, per frate focu

TERRESTRE

per lo quale ennallumini la nocte

et ello è bello et iocundo et robustoso

et forte.

Laudato si', mi Signore, per sora nostra matre terra,

la quale ne ustenta et governa

23 et produce diversi fructi con coloriti

fiori er herba

Agora, na superfície terrestre, o Senhor seja louvado na personificação fraterna do elemento água, em cuja limpidez e transparência se unificam os atributos espirituais da humildade, da utilidade e da pureza.

Sobre a face da Terra, o símbolo mais vivo e mais forte da existência em contraponto com a água, e, irradiando na Terra, como 
no céu o sol, merece louvor o irmão Fogo, que é belo, vigoroso e forte, aquecendo os entes e iluminando alegremente os ânimos.

A sequiência dos adjetivos, além de imprimir ao ritmo do verso uma cadência regular e forte, mais do que a abstração dos substantivos correspondentes, transmite-nos toda a força poética que está nas qualidades íntimas de cada ser, descritas e intensamente misturadas aos sentimentos que suscitam:

"et ello à bello et jocundo et robustoso et forte"

A arquitetura do universo completa-se com a exaltação de nossa irmã e mãe terra, fonte da vida material e depositária da beleza exuberante dos frutos e das flores coloridas que enchem de alegria os nossos sentidos.

Até a esta altura do poema, o poeta leva-nos à contemplação dos encantos do mundo visceral, traduzido em imagens de um extraordinário vigor plástico e profano. A poesia brota por si, como as fontes de beleza que a própria natureza nos oferece.

A natureza é o grande quadro, de cores e de luzes, para onde o poeta voltará a sua contemplação, a partir dos versos seguintes:

E o PARAISO MORAL DOS BEMAVENTURADOS, que vai do verso 24 ao 32 .

São Francisco exorta os șantos que estão no Universo exterior, onde os felizes mortais que, perdoando por causa do amor de Deus, por ele suportam a doença $e$ as tribulações.

Eles são os pacíficos e possuirão a glória de Deus:

24 Laudato si', mi Signore, per quelli che Universo perdonano per lo tuo amore exterior et sostengo infirmitate et tribulatione, beati quelli chel sosterra( $n$ )o in pace

27 ca da te, altissimo, sirano incoronati.

28 Laudato si', mi Signore, per sora nostra morte corporale

Passagem da la quale nullu homo vivente po scappare,

30 guai a quelli che $\operatorname{morran}(n) o$ ne le peccata mortali beati quelli che trovarà ne le tue interior sanctissim evoluntati car la morte seconda nol far(r)à male. 
33 Laudate et benedicete $\mathrm{mi}$ Signore et rengratiate

et serviteli cu mgrande humiliatte.
Hino fi-

nal de

louvor a

Deus

Pela última vez, a expressão "laudato si" " refere-se à exortação, agora, da morte corporal, irmanando os elementos da vida física no mesmo processo de santificação.

Os versos 28 e 29 , em que é louvada a irmã morte, representam, ainda dentro do plano da arquitetura poética do Cântico, a última passagem do Universo exterior, onde os santos serão coroados, para o Universo interior, subjetivo, totalmente interiorizado na santa vontade divina, onde os mortos descansarão em paz.

Com essa estrofe, faz-se a passagem da vida ativa para a vida contemplativa do homem, mas esta se inicia com uma espantosa advertência:

"Guai a quelli che morran(n)o ne le peccata mortali"

Este verso é como que um mergulho, ainda que rápido, nas profundezas do abismo, uma antevisão terrível do que seria o inferno, a destruição do espírito humano; abatido pelo pecado mortal, ausência absoluta de Deus.

Mas, como dissemos, o sonho de S. Francisco é muito mais generoso e anseia pela redenção total da humanidade; a sua bondade volta, rapidamente, a contemplar a felicidade daqueles em que a destruição da alma não se fará porque estarão em conformidade com a vontade de Deus, pois só assim a morte corporal não lhes fará mal.

A irmã morte corporal é, aqui, bem distinta da morte espiritual, ou seja, numa das mais célebres criações poéticas, São Francisco consagrou como "la morte secunda", e, que mais tarde, será retomada por Dante.

Como vimos, o tema de louvor a Deus abre o Cântico, de modo solene e absoluto, pois o Senhor é o objeto único de adoração e reverência. O homem, posto em confronto imediato com a face divina aparece em sua pequenez e em sua indignidade, que é tāo maior, quanto mais próximo ele se encontra do Criador

Essa viva oposição, ressaltada pelo poeta no verso 5: "et nullu homo ene dignu te mentovare", inclui não só "quelli che morrano 
ne le peccata mortali" mas todos, inclusive os santos; é a projeção autêntica do conceito em que se tinha o próprio frade: "último entre os seus" Mas ela se abranda nos versos finais do poema, em que toda a humanidade de fiéis e pecadores são exortados a louvá-lo e bendizê-lo, servindo-o com grande humildade.

O fecho do poema se faz com o termo ínfimo humilitate, com a qual se prostam as criaturas diante do altissimu, inicial.

A dignificação dos seres inanimados elevados à categoria de irmãos dos homens do Senhor, envolvidos pelo arrebatamento ingênuo do poeta, é a grande originalidade do poema franciscano.

A contribuição de São Francisco para a literatura vulgar reduzse quase que exclusivamente a essa obra, única, apesar de tardia.

Nem assim o tema das laudes, pela imitação ou pela difusão, se desenvolverá, decisivamente, na literatura vulgar italiana.

Fora a tradição hagiográfica, confinada à piedosa curiosidade dos seus seguidores, esse tema do Cântico, em contraste com as fontes evangélicas em que é inspirado, compõe-se em outro nível: os seres terrenos, inanimados, que, juntamente com o Senhor, ou como ele, recebem $o$ ato de louvação, aparecem numa ordem determinada, de acordo com o sentido cosmogônico da palavra, isto é, na ordem das quatro energias primordiais do universo: o ar, a água, o fogo e a terra. Funde-se, ainda, ao conceito dos quatro elementos tradicionais, a outra série tríplice de criaturas: o céu, o ar e a terra, conceito basilar de certas mitologias pagãs (Benedetto, op. cit., p. 31), as quais se transfiguram num espetáculo de amor e de alegria cristãs, tudo como irmãos no Senhor.

Laudato si', mi Signore, é a fórmula laudatória que se repete no início de quase todas as estrofes, e às quais imprime monotonia sagrada do salmo (14), mas é pelas oito repetições da preposição per, regendo os substantivos "irmão e irmã", no verso 24 , regendo o pronome "quelli", e, ainda, pela preposição cum do verso 6 , às quais damos o sentido de assim como, que aceitamos a interpretação de modernos críticos, e vemos instaurada a novidade temática do Cântico.

(14) - O Salmo de Davi e o Livro de Daniel foram lidos em Biblia Sagrada, S. P., Ed., Ave Maria Ltda., trad. dos orig., hebraico, aramaico e grego med. a versão fr. dos Monges Bende. de Maredsous (Belg.), C. B. Cat. de S. P., $2^{a}$ ed. 
Diversamente dos que antevêem, nesse tema, o naturalismo renascentista com a sua curiosidade pela natureza, qual dimensão da liberdade humana, já bem distante da idéia de Deus, São Francisco é um exemplo típico do espírito medieval, pois continua a ver em cada coisa sensível o símbolo de um conceito divino (Getto, op. cit.).

Todo o Cântico é envolvido pelo sentimento ingênuo de pureza que as coisas, no seu estado original, oferecem ao homem Francisco, deslumbrado pela virgindade delas.

O profundo lirismo que emana do poema é uma correspondência íntima com o grande sonho de São Francisco: fazer da vida na Terra uma antecipação do Paraíso, isto é, uma imensa e perpétua adoração, fazer do mundo inteiro "uma pura e santa Porciúncula" (Spec. Perf., p. 105), inteiramente ressonante de hinos e laudes ao Deus dos céus. 